\title{
SPATIAL GENETIC STRUCTURE OF THE TALLGRASS PRAIRIE GRASS DICHANTHELIUM OLIGOSANTHES (SCRIBNER'S PANICUM)
}

\author{
Molly J. Parkhurst ${ }^{1}$ \\ Andrew Doust ${ }^{1}$ \\ Margarita Mauro-Herrera ${ }^{1}$ \\ Jeffrey M. Byrnes ${ }^{2}$ \\ Janette A. Steets ${ }^{1}$ \\ janette.steets@okstate.edu
}

\author{
${ }^{1}$ Oklahoma State University \\ Department of Botany \\ 301 Physical Sciences \\ Stillwater, OK 74078 \\ ${ }^{2}$ Oklahoma State University \\ Boone Pickens School of Geology \\ 105 Noble Research Center \\ Stillwater, OK 74078
}

\begin{abstract}
Keywords: Mixed-mating system, population differentiation, population genetic structure
\end{abstract}

\begin{abstract}
The spatial genetic structure within plant populations and genetic differentiation among populations can vary in strength due to the forces of natural selection, gene flow and genetic drift. In this study, we investigate the level of genetic structure and differentiation present in Oklahoma populations of Dichanthelium oligosanthes (Schult.) Gould (Scribner's panicum), a $\mathrm{C}_{3}$ grass native to the United States and a frequent member of the tallgrass prairie. To examine fine-scale spatial genetic structure of $D$. oligosanthes, we collected leaves from 48 spatially separated plants in a population in Stillwater, OK. To examine genetic differentiation among adjacent populations, we sampled leaf tissue from eight individuals at each of three populations in Stillwater, OK. DNA was extracted from these samples and Inter-Simple Sequence Repeats (ISSR) markers were amplified. Within a single population of $D$. oligosanthes, we found a weak and non-significant negative relationship between genetic similarity and geographical distance. In contrast, we found evidence for moderate and significant genetic differentiation among populations.

\section{INTRODUCTION}

Genetic variation is the sum total of all genetically based variation within and among species and represents an important component of biodiversity. Maintaining genetic variation within and among native plant populations is a central goal of conservation biology, as genetic variation provides the raw material for plants to evolve in response to environmental change and contributes to population fitness (Leimu et al. 2006, Reed and Frankham 2003, Wagner et al. 2011). Given the importance of genetic variation for the maintenance and evolution of plant populations, it is critical to understand the levels of genetic diversity

within species and determine how this variation is organized spatially, both within and between populations.

The way in which genetic variation is organized within plant populations (spatial genetic structure) is affected by many factors, including selection pressures within a population, mating system (relative production of selfed to outcrossed individuals), and whether gene flow is restricted (Loiselle et al. 1995, Loveless and Hamrick 1984, Miyazaki and Isagi 2000, Perry and Knowles 1991). Plants are sessile organisms and gene flow can only occur through pollen and seed movement. Restricted dispersal of seed or pollen can
\end{abstract}


occur due to the dispersal mechanism utilized by the plant, the presence of physical barriers, and when rates of inbreeding are high. Under these conditions, population genetic structure is predicted to develop, with a clustering of genetically related individuals among plants within a population and a high level of genetic differentiation among geographically separated populations (Epperson and Li 1997, Hamrick and Nason 1996).

Dichanthelium oligosanthes is a short, $\mathrm{C}_{3}$ perennial grass native to the United States that is commonly found in open prairies, meadows, and disturbed areas (Kansas State University Libraries 2011). Although it is not a dominant species of the tallgrass prairie, it is a highly consistent member of this community (Adams and Wallace 1985).

The mating system and ecology of D. oligosanthes are likely to affect population genetic structure. First, D. oligosanthes has a mixed mating system resulting from the production of two types of flowers within a single individual: closed, self-fertilizing cleistogamous flowers and open, potentially outcrossing chasmogamous flowers. The chasmogamous flowers form on a terminal panicle in May - June, are open-pollinated for a short time, then close and self-fertilize in the absence of pollination (Bell and Quinn 1985, Freckmann and Lelong 2003). The cleistogamous flowers extend from within the sheath and appear from June - November (Bell and Quinn 1985, Freckmann and Lelong 2003). Grasses in the genus Dichanthelium tend to reproduce proportionately more through cleistogamy than through chasmogamy (Bell and Quinn 1985, Bell and Quinn 1987). This high rate of self-fertilization should lead to significant spatial genetic structure within populations and genetic differentiation among populations. Second, as an element of the tallgrass prairies, $D$. oligosanthes has a relatively short stature of less than $45 \mathrm{~cm}$. In tallgrass prairies, D. oligosanthes is imbedded within a matrix of the dominant grass species (Andropogon gerardii, Panicum virgatum, Sorgastrum nutans, and Schizachyrium scoparium). These dominant grasses can reach heights of up to 2 m (USDA, NRCS 2011) and thus may serve as a physical barrier to $D$. oligosanthes pollen and seed dispersal, further contributing to spatial genetic structure within populations. In contrast to the first two factors, which would tend to increase fine-scale spatial genetic structure within $D$. oligosanthes populations, one aspect of $D$. oligosanthes fruit dispersal could lead to reduced genetic structure. In particular, the fruits of $D$. oligosanthes can disperse great distances when the inflorescence breaks off of the plant, leading to a "tumbleweed" dispersal mechanism (Campbell et al. 1983).

We examined spatial genetic structure and population differentiation of $D$. oligosanthes in Stillwater, OK. Through our study we aimed to answer the following questions: (1) How is genetic diversity distributed spatially within a population of $D$. oligosanthes? (2) Are populations of $D$. oligosanthes genetically differentiated? To address these questions, we examined genetic diversity in Inter-Simple Sequence Repeats (ISSR) markers in three D. oligosanthes populations. Within a single population of $D$. oligosanthes, we expected genetically related individuals to be aggregated spatially, and thus we expected to find a negative correlation between genetic similarity and geographical distance. Among populations of $D$. oligosanthes, we expected to find a significant degree of genetic differentiation.

\section{MATERIALS AND METHODS}

\section{How is genetic diversity distributed spatially within a population of D. oligosanthes?}

We collected leaf samples from 48 representatives of $D$. oligosanthes from the southern portion of the Oklahoma State University (OSU) Cross Country Field South in Stillwater, OK (CCS population: 3608'12.0”N, 9704'36.6”W; Figure 1). Thirty-eight of these samples were located across three approximately parallel transects,

Parkhurst, M. J., et al. 
each approximately $36 \mathrm{~m}$ in length and five to ten $m$ apart. Material from an additional ten plants was collected at increasing distances from these transects. Locations of all plants were recorded using a Trimble $2008 \mathrm{GeoXH}$ handheld GPS with an external Zephyr antenna and were differentially corrected relative to a stationary base station to increase the accuracy of the GPS data. The locations of each of the 48 plant samples were mapped on an aerial photograph of the site (see Figure $1)$.

We extracted DNA from each individual following the procedure of Junghans and Metzlaff (1990). For each sample, genomic DNA concentrations were quantified using NanoDrop spectrophotometry and 1\% agarose gel electrophoresis. We tested 12 ISSR markers (Zietkiewicz et al. 1994) from the UBC primer set \#9 (University of British Columbia Nucleic Acid-Protein Service Unit) and successfully amplified five of these via polymerase chain reaction (PCR) (Table 1). We ran $10 \mu \mathrm{L}$ PCRs using $1 \mu \mathrm{L}$ of diluted genomic DNA (from a 1:30 dilution corresponding to 10 to $20 \mathrm{ng}$ of genomic DNA), dNTPs at $100 \mu \mathrm{M}$ each, ISSR primer at $0.5 \mu \mathrm{M}, 1 \mathrm{X}$ Green Go'Taq ${ }^{\circledR}$ Flexi Buffer (Promega, Madison, WI), $\mathrm{MgCl}_{2}$ at $1.5 \mathrm{mM}$, and 0.6 units of Promega Go Taq polymerase (Promega, Madison, WI). Amplifications were performed in an Eppendorf Mastercycler Pro thermal cycler using the following touchdown conditions: single initial denaturation step at $95^{\circ} \mathrm{C}$ for two minutes; followed by 32 cycles each with three steps: a denaturation step at $94^{\circ} \mathrm{C}$ for 40 seconds, followed by an annealing touchdown step (starting at $56^{\circ} \mathrm{C}$ or $58^{\circ} \mathrm{C}$, depending on the primer, for two cycles; then $54^{\circ} \mathrm{C}$ or $56^{\circ} \mathrm{C}$ for two cycles to reach $52^{\circ} \mathrm{C}$ or $54^{\circ} \mathrm{C}$ for 28 cycles) for 40 seconds, and an extension step at $72^{\circ} \mathrm{C}$ for 50 seconds; and a final extension at $72^{\circ} \mathrm{C}$ for eight minutes. PCR products were resolved electrophoretically on 1\% agarose gels run at $150 \mathrm{~V}$ in TBE buffer, visualized by staining with ethidium bromide, and photographed under UV illumination. Fragment sizes were estimated using Hyper Ladder II (Bioline, Tauton, MA). ISSR bands were scored as present or absent for each plant sample. Bands were scored and compared by two different people to reduce subjectivity in the scoring procedure. Twelve individuals showed poor amplification of some of the ISSR markers, resulting in missing data in the dataset. As the statistical analyses described below do not allow for missing data, we eliminated these individuals from further analysis. Thus, the analysis of genetic structure in the CCS population used a total of 36 individuals.

Geographical distances between plants were estimated using Euclidean distances. Genetic similarities between plants were estimated using a matrix of Dice genetic similarity coefficients created with the PAST program (Hammer et al. 2001). The Dice coefficient, which weighs positive matches between plant samples and ignores negative matches, was used because ISSRs are dominant markers, and therefore only the presence of a PCR product is meaningful. A Mantel test was performed to determine whether there was a relationship between geographical distance and genetic similarity with both the PAST program and the at program (Bonnet and Van der Peer 2009), using 10,000 permutations of the data. Finally, to examine hierarchal clustering in the samples, we generated an Unweighted Pair Group Method with Arithmetic mean (UPGMA) tree of the genetic distance data using the PAST program (Hammer et al. 2001). A bootstrap analysis using 1000 replications was performed to determine the support for the hierarchical clustering.

\section{Are populations of $D$. oligosanthes genetically differentiated?}

To determine whether nearby populations of D. oligosanthes in Stillwater, OK are genetically differentiated from one another, we examined the diversity of six ISSR markers (see Table 1) in three populations (Figure 2): OSU Cross Country Field South (CCS; 
3608'12.0”'N, 9704'36.6”'W), OSU Cross Country Field North (CCN; 36 $08^{\circ} 20.8^{\prime \prime} \mathrm{N}$, $\left.97^{\circ} 04^{\prime} 39.9^{\prime \prime} \mathrm{W}\right)$, and Lakeview Road West (LW; 3608'42.6”N, 9705'38.9'”). Populations CCS and CCN were separated from one another by $0.3 \mathrm{~km}, \mathrm{CCN}$ and LW by $1.6 \mathrm{~km}$ and CCS and LW by $1.8 \mathrm{~km}$. Within each of the three populations, we collected leaf material from eight randomly chosen individuals. We extracted DNA, amplified ISSR markers via PCR, and visualized PCR products via gel electrophoresis as described above.

We used the program Hickory version 1.1 (Holsinger and Lewis 2003, Holsinger et al. 2002) to estimate genetic differentiation among populations of $D$. oligosanthes. Hickory allows for estimation of heterozygosity within populations and genetic differentiation among populations using dominant markers without assuming Hardy-Weinberg equilibrium (Holsinger and Lewis 2003, Holsinger et al. 2002). This program uses Bayesian methods to estimate the average heterozygosity within subpopulations ( $h s$; an analog of the expected heterozygosity) and test for genetic differentiation among populations through the unbiased estimate $\theta^{I}$, which is analogous to Weir and Cockerham's (1984) $\mathrm{F}_{\mathrm{ST}}$ (Holsinger and Lewis 2003). $\theta^{I I}$ measures the amount of genetic differentiation among contemporaneous populations (Holsinger and Lewis 2003); values close to 0 suggest little genetic differentiation between populations (i.e., complete panmixia), whereas values close to one suggest genetic isolation between populations.
The D. oligosanthes ISSR data were fitted to four models: (1) full (uses non-informative priors for $f$ ), (2) $f=0$ (assumes no inbreeding; $f$ is analogous to the inbreeding coefficient $\mathrm{F}_{\mathrm{IS}}$ ), (3) $\theta^{I I}=0$ (assumes no population differentiation), and (4) $f$-free (decouples the estimation of $\theta^{I I}$ from the estimation of $f$ ). In each model run, the default parameters were used (burn-in $=5,000$; number of samples $=$ 25,000; thinning $=5$ ). The models were compared to one another based on the deviance information criterion (DIC) of Spiegelhalter et al. (2002) implemented in Hickory. The full model best fit our dataset as it provided the lowest DIC value; thus, we present the results of the full model in the Results section.

\section{RESULTS}

\section{How is genetic diversity distributed spatially within a population of $D$. oligosanthes?}

The five ISSR primers produced a total of 21 loci that could be reliably scored in the CCS population, of which 13 were polymorphic (Table 2).

The Mantel test revealed a non-significant negative relationship between genetic similarity and geographic distances, with a negative correlation between geographical distance and similarity $(r=-0.042, P=0.755)$. The UPGMA analysis revealed weak hierarchical clustering among the plant samples, consistent with the results of the Mantel test (data not shown). Thus, we find no evidence for significant spatial genetic structure in the CCS population of D. oligosanthes. 


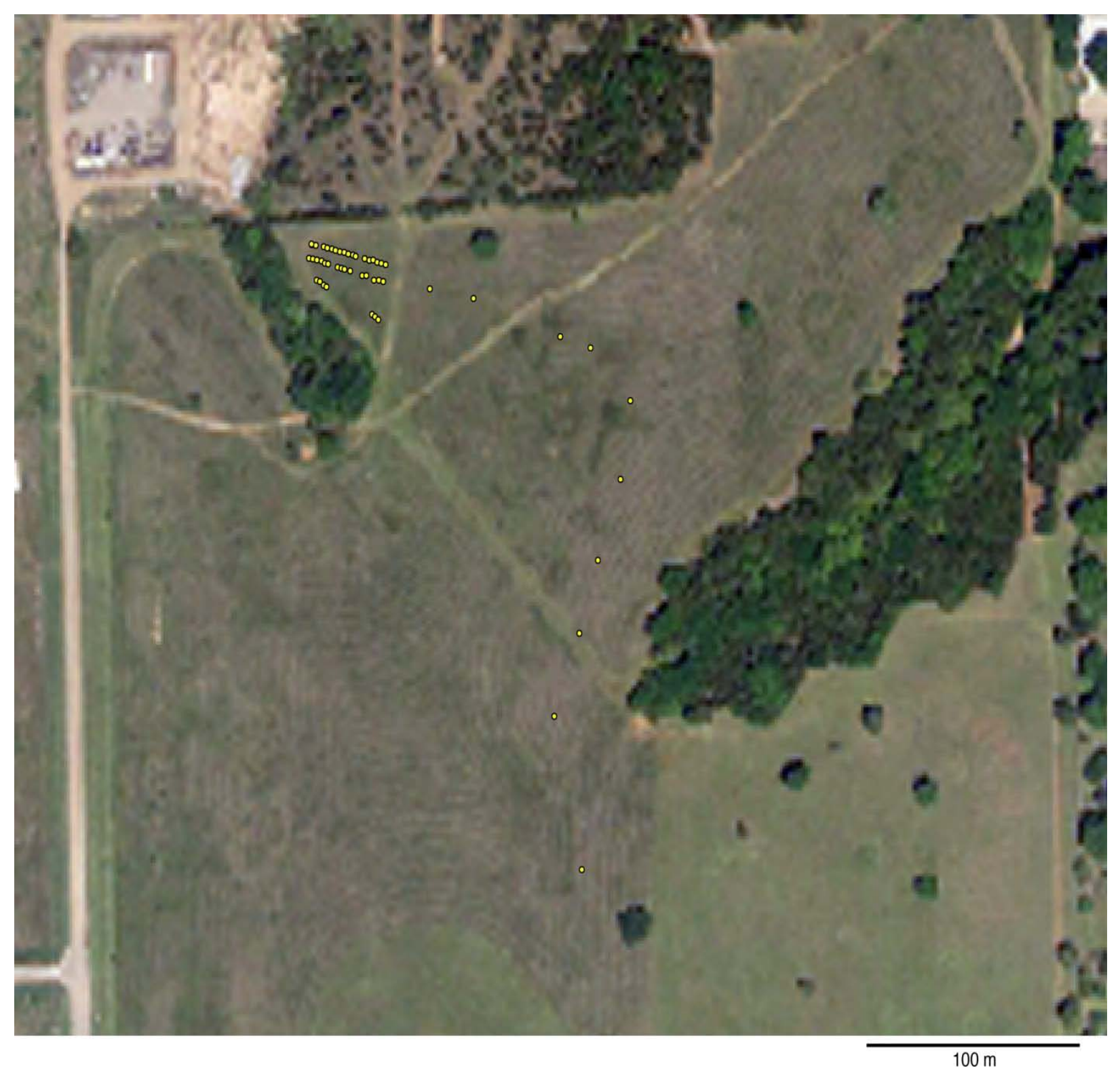

Figure 1 Map of the Oklahoma State University Cross Country Field South (CCS) Dichanthelium oligosanthes population in Stillwater, OK. Yellow points indicate the location of D. oligosanthes plants sampled; base image is an aerial photograph acquired by the USDA Farm Service Agency. 


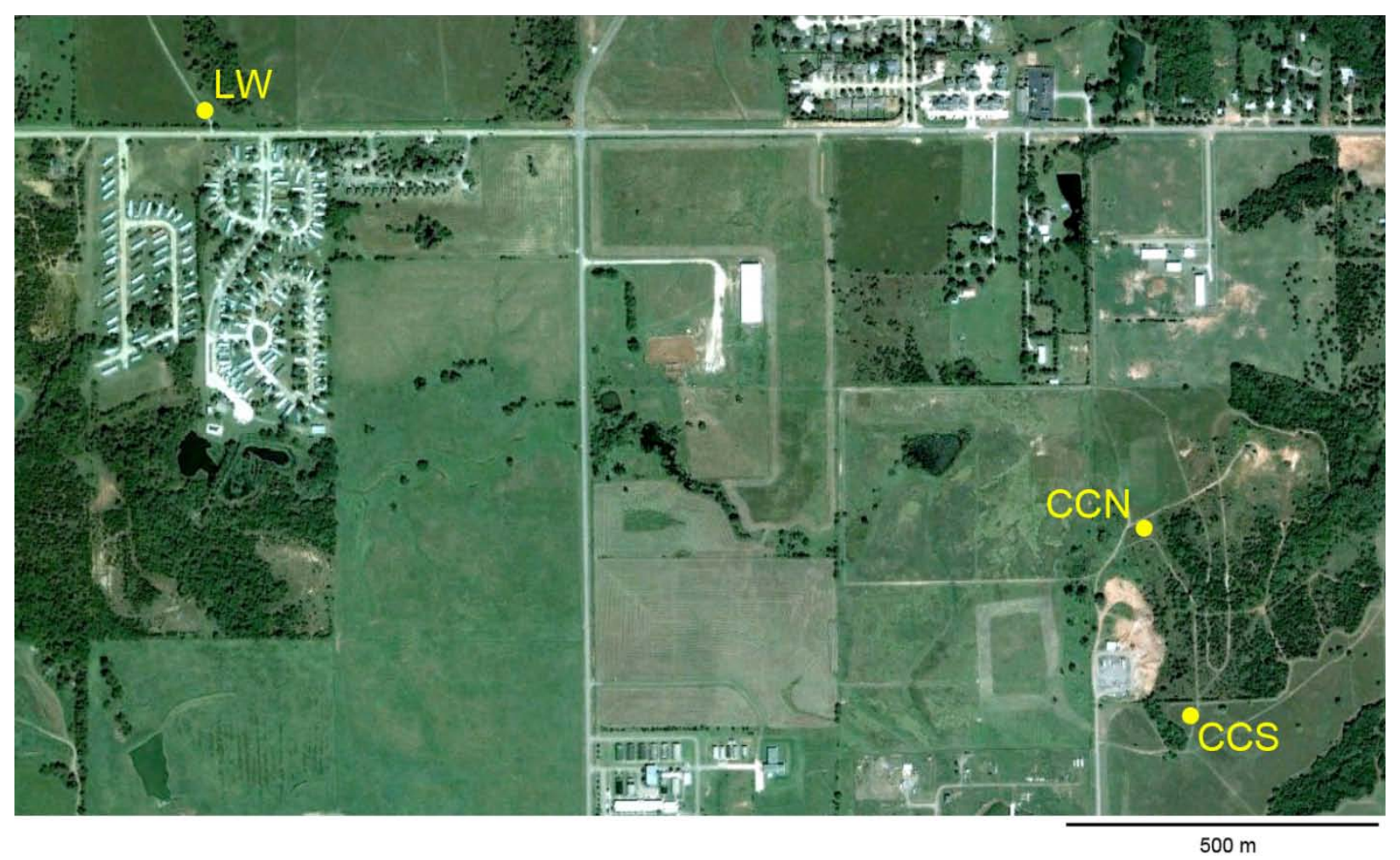

Figure 2 Map of Dichanthelium oligosanthes populations in Stillwater, OK; base image from Google Earth. CCS = Oklahoma State University (OSU) Cross Country Field South, CCN = OSU Cross Country Field North, LW = Lakeview Road West.

Table 1 ISSR primers used for DNA amplification from UBC primer set \#9 (University of British Columbia Nucleic Acid-Protein Service Unit). The right-most column indicates whether the given primer was used in the study of genetic diversity in the Oklahoma State University Cross Country Field South population of D. oligosanthes (A) and/or the study of genetic differentiation among three Stillwater, OK populations of D. oligosanthes (B).

\begin{tabular}{clc}
\hline Primer & \multicolumn{1}{c}{ Sequence $\left(5^{\prime}-3^{\prime}\right)$} & Study using primer \\
\hline UBC -808 & AGA GAG AGA GAG AGA GC & B \\
UBC -809 & AGA GAG AGA GAG AGA GG & A and B \\
UBC -810 & GAG AGA GAG AGA GAG AT & A and B \\
UBC -816 & CAC ACA CAC ACA CAC AT & A and B \\
UBC -817 & CAC ACA CAC ACA CAC AA & A and B \\
UBC -818 & CAC ACA CAC ACA CAC AG & A and B \\
\hline
\end{tabular}

Parkhurst, M. J., et al. 
Table 2 Numbers of loci reliably scored, numbers of polymorphic loci, and percentage of polymorphic loci for each of the five ISSR primers used in the study of genetic diversity in the Oklahoma State University Cross Country Field South (CCS) population of D. oligosanthes.

\begin{tabular}{lccc}
\hline Primer & $\begin{array}{c}\text { Number of loci } \\
\text { reliably scored }\end{array}$ & $\begin{array}{c}\text { Number of reliably } \\
\text { scored polymorphic } \\
\text { loci }\end{array}$ & $\begin{array}{c}\text { Percentage } \\
\text { polymorphic loci }\end{array}$ \\
\hline UBC -809 & 6 & 3 & 50.0 \\
UBC -810 & 4 & 2 & 50.0 \\
$\mathrm{UBC}-816$ & 5 & 2 & 40.0 \\
$\mathrm{UBC}-817$ & 3 & 3 & 100.0 \\
$\mathrm{UBC}-818$ & 3 & 3 & 100.0 \\
Total & 21 & 13 & 61.9 \\
\hline
\end{tabular}

${ }^{1}$ For all primers, additional bands were present but could not be reliably scored (i.e., band was weak or too close to adjacent band). The number of loci reliably scored does not include these additional unscored bands.

${ }^{2}$ Given that bands that could not be reliably scored were excluded from this calculation, this is an approximate percentage of polymorphic loci.

Table 3 Number of loci reliably scored, number of polymorphic loci, and percentage of polymorphic loci for each of the six ISSR primers used in the study of genetic differentiation among three D. oligosanthes populations in Stillwater, OK.

\begin{tabular}{lccc}
\hline Primer & $\begin{array}{c}\text { Number of loci } \\
\text { reliably scored }\end{array}$ & $\begin{array}{c}\text { Number of reliably } \\
\text { scored polymorphic } \\
\text { loci }\end{array}$ & $\begin{array}{c}\text { Percentage } \\
\text { polymorphic loci }^{2}\end{array}$ \\
\hline UBC -808 & 13 & 4 & 30.8 \\
UBC -809 & 6 & 3 & 50.0 \\
UBC -810 & 7 & 5 & 71.4 \\
UBC -816 & 8 & 5 & 62.5 \\
UBC -817 & 4 & 4 & 100.0 \\
UBC -818 & 3 & 3 & 100.0 \\
Total & 41 & 24 & 58.5 \\
\hline
\end{tabular}




\section{Are populations of $D$. oligosanthes genetically differentiated?}

The six ISSR primers produced a total of 41 loci that could be reliably scored, of which 24 were polymorphic across the three populations (Table 3 ). In the CCS and LW populations $51.2 \%$ of the 41 ISSR loci were polymorphic and in the CCN population $53.7 \%$ were polymorphic. The average heterozygosities $(h s)$ within each of the three populations were similar (mean \pm s.d.; CCS: $0.36 \pm 0.022, \mathrm{CCN}: 0.35 \pm 0.023, \mathrm{LW}: 0.37 \pm$ 0.020 ), indicating that genetic diversity does not differ drastically among the populations. On average, $h s$ was $0.36 \pm 0.016$ across the three populations.

In the Bayesian analysis of population genetic differentiation using the full model, $\theta^{I}$ (analogous to Weir and Cockerham's (1984) $\mathrm{F}_{\mathrm{ST}}$ ) was estimated to be 0.134 (s.d. $=0.0428$ ), indicating a moderate proportion of differentiation among populations.

\section{DISCUSSION}

Given the central role of genetic diversity in the evolutionary process, it is critical to understand how genetic diversity is distributed within and among populations. In this study, we found no evidence for fine-scale spatial genetic structure within a single population of D. oligosanthes. However, we found significant levels of genetic differentiation among three $D$. oligosanthes populations. Below we expand on these findings and discuss potential factors contributing to the patterns of genetic structure and differentiation observed in

\section{D. oligosanthes.}

In the CCS population of D. oligosanthes, we found a negative but non-significant relationship between genetic similarity and geographic separation of plants. The lack of significance is contrary to our expectations, although the trend fits our hypothesis that plants in close spatial proximity to one another were more genetically similar than plants that were more spatially separated.
Such findings can be contrasted with those of other plant species, such as the self-

compatible annual herb Polygonum thunbergii. In this species, Konuma and Terauchi (2001) found a significant negative correlation between genetic similarity and geographic distance $(r=-0.64)$. The difference in finescale spatial genetic structure of these plant species may be due to differences in seed dispersal. Grasses in the genus Dichanthelium may disperse fruits over greater distances as the inflorescence breaks off of the plant, leading to a "tumbleweed" dispersal of the fruits (Campbell et al. 1983). In contrast, P. thunbergii shows restricted seed dispersal, with seeds being dispersed in close proximity to the maternal plant (Konuma and Terauchi 2001). An additional factor that may contribute to the non-significant relationship found between genetic similarity and geographic distance in the CCS population of $D$. oligosanthes is low germination and recruitment of selfed (i.e., cleistogamous) individuals. However, in a related Dichanthelium species, D. clandestinum, Bell and Quinn (1985) found that cleistogamous seeds germinated and emerged, both in the greenhouse and in the field, at a higher rate than chasmogamous seeds. Future work is needed in $D$. oligosanthes to determine whether differences in cleistogamous and chasmogamous germination and recruitment may contribute to the observed patterns in spatial genetic structure.

We found significant levels of genetic differentiation among three $D$. oligosanthes populations. This pattern of genetic differentiation could be due to the cleistogamous mating system of $D$. oligosanthes. Grasses in the genus Dichanthelium tend to reproduce proportionately more through cleistogamy than through chasmogamy (Bell and Quinn 1985, Bell and Quinn 1987). With elevated levels of inbreeding, genetic differentiation between populations is expected. The differentiation we observed amongst three neighboring populations of $D$. oligosanthes indicates that it is necessary to

Parkhurst, M. J., et al. 
conserve multiple populations of this species to maintain genetic diversity.

\section{ACKNOWLEDGEMENTS}

Funding for this study was provided by National Science Foundation through Oklahoma Louis Stokes Alliance for Minority Participation and Oklahoma State University. Special thanks to Theresa Henley for the aerial photograph used as the base for Figure 1.

\section{LITERATURE CITED}

Adams, D. E. and L. L. Wallace. 1985. Nutrient and biomass allocation in five grass species in the Oklahoma tallgrass prairie. American Midland Naturalist 113:170-181.

Bell, T. J. and J. A. Quinn. 1985. Relative importance of chasmogamously and cleistogamously derived seeds of Dichanthelium clandestinum (L.) Gould. Botanical Gazette 146:252-258.

Bell, T. J. and J. A. Quinn. 1987. Effects of soil moisture and light intensity on the chasmogamous and cleistogamous components of reproductive effort of Dichanthelium clandestinum populations. Canadian Journal of Botany 65:2243-2249.

Bonnet, E. and Y. Van der Peer. 2009. zt: a software tool for simple and partial Mantel tests. (http:/ /www.psb.ugent.be/ $\sim$ erbon/mantel/).

Campbell, C. S., J. A. Quinn, G. P. Cheplick, and T. J. Bell. 1983. Cleistogamy in grasses. Annual Review of Ecology and Systematics 14:411-441.

Epperson, B. K. and T. Li. 1997. Gene dispersal and spatial genetic structure. Evolution 51:672-681.

Freckmann, R. W. and M. G. Lelong. 2003. Dichanthelium. M. E. Barkworth, K. M. Capels, S. Long, and M. B. Piep (eds.). Flora of North America North of Mexico, Vol. 25. New York.

Hammer, O., D. A. T. Harper, and P. D. Ryan. 2001. PAST: Paleontological
Statistics Software Package for Education and Data Analysis. Paleontologia Electronica 4:9. (http://palaeo-electronica.org/2001 _1/past/issue1_01.htm).

Hamrick, J. L. and J. D. Nason. 1996. Consequences of dispersal in plants. In: O. E. Rhodes, R. K. Chesser, and M. H. Smith (eds.). Population Dynamics in Ecological Space and Time. The University of Chicago Press, Chicago, Illinois.

Holsinger, K. E. and P. O. Lewis. 2003. Hickory: A Package for Analysis of Population Genetic Data, version 1.1. Department of Ecology and Evolutionary Biology, University of Connecticut Storrs, Connecticut. (http:// darvin.eeb.uconn.edu/ hickory/hickory.htmo).

Holsinger, K. E., P. O. Lewis, and D. K. Dey. 2002. A Bayesian approach to inferring population structure from dominant markers. Molecular Ecology 11:1157-1164.

Junghans, H. and M. Metzlaff. 1990. A simple and rapid method for the preparation of total plant DNA. Biotechniques 8:176.

Kansas State University Libraries. 2011. Scribner Dichanthelium. (M. Haddock, Editor) Retrieved June 29, 2011, from Kansas Wildflowers and Grasses: www.kswildflowers.org.

Konuma, A. and R. Terauchi. 2001. Population genetic structure of the selfcompatible annual herb; Polygonum thunbergii (Polygonaceae) detected by multilocus DNA fingerprinting. American Midland Naturalist 146:22-127.

Leimu, R., P. Mutikainen, J. Koricheva, and M. Fischer. 2006. How general are positive relationships between plant population size, fitness, and genetic variation. Journal of Ecology 94:942-952.

Loiselle, B. A., V. L. Sork, J. Nason, C. Graham. 1995. Spatial genetic structure of a tropical understory shrub, Psychotria officinalis (Rubiaceae). American Journal of Botany 82:1420-1425.

Loveless, M. D. and J. L. Hamrick. 1984. Ecological determinants of genetic 
structure of plant populations. Annual Review of Ecology and Systematics 15:65-95. Miyazaki, Y. and Y. Isagi. 2000. Pollen flow and the intrapopulation genetic structure of Heloniopsis orientalis on the forest floor as determined using microsatellite markers. Theoretical Applied Genetics 101:718-723.

Perry, D. J. and P. Knowles. 1991. Spatial genetic structure within three sugar maple (Acer saccharum Marsh.) stands. Heredity 66:137-142.

Reed, D. H. and R. Frankham. 2003. Correlation between fitness and genetic diversity. Conservation Biology 17:230-237.

Spiegelhalter, D. J., N. G. Best, B. R. Carlin, and A. van der Linde. 2002. Bayesian measures of model complexity and fit. Journal of the Royal Statistical Society, B, Methodological 64:583-616.
USDA, NRCS. 2011. The PLANTS Database (http:/ / plants.usda.gov, 23 June 2011). National Plant Data Center, Baton Rouge, LA.

Wagner, V., W. Durka, and I. Hensen. 2011. Increased genetic differentiation but no reduced genetic diversity in peripheral vs. central populations of a steppe grass. American Journal of Botany 98:1173-1179.

Weir, B. S. and C. C. Cockerham. 1984. Estimating $F$-statistics for the analysis of population structure. Evolution 38:13581370.

Zietkiewicz, E., A. Rafalski, and D. Labuda. 1994. Genome fingerprinting by simple sequence repeat (SSR)-anchored polymerase chain reaction amplification. Genomics 20:176-183.

Parkhurst, M. J., et al. 